\title{
Erratum
}

\section{Erratum for Vol. 56, No. 3, page 135: \\ Sonic Boom Analysis under Conditions of Atmospheric Uncertainty Using Polynomial Chaos}

By Shinkyu Jeong, ${ }^{1)}$ Daichi Ono, ${ }^{2)}$ Koji Shimoyama ${ }^{2)}$ and Atsushi Hashimoto ${ }^{3)}$

\author{
${ }^{1)}$ Department of Mechanical Engineering, Kyunghee University, Yongin, Korea \\ ${ }^{2)}$ Institute of Fluid Science, Tohoku University, Sendai, Japan \\ 3) Japan Aerospace Exploration Agency, Chofu, Japan
}

Wrong graphics have been inserted in Figures 8 and 9 each other. Sorry for any confusion and inconvenience.

Wrong:

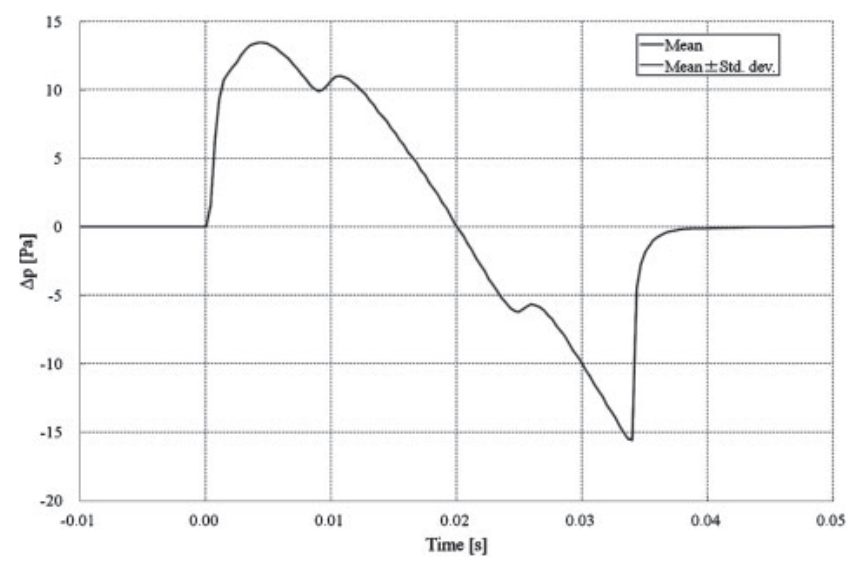

Fig. 8. Sonic boom signature under conditions of humidity uncertainty.

Right:

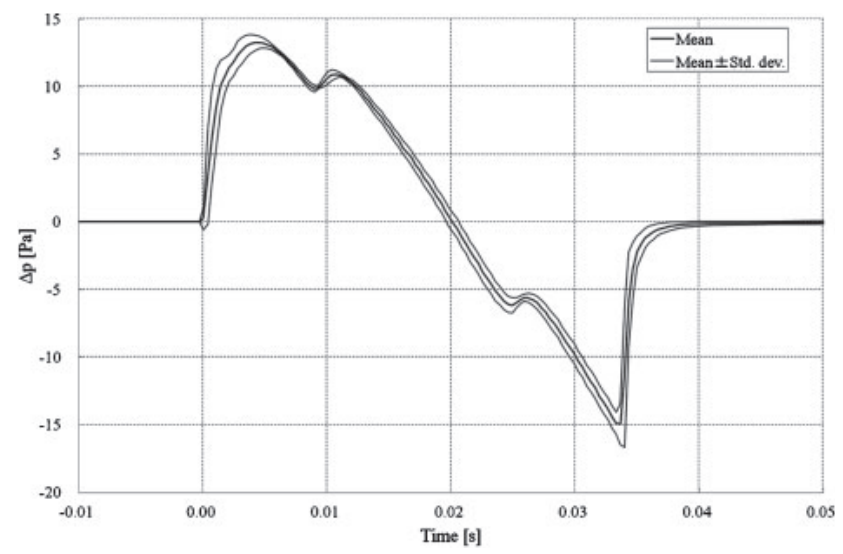

Fig. 8. Sonic boom signature under conditions of humidity uncertainty.

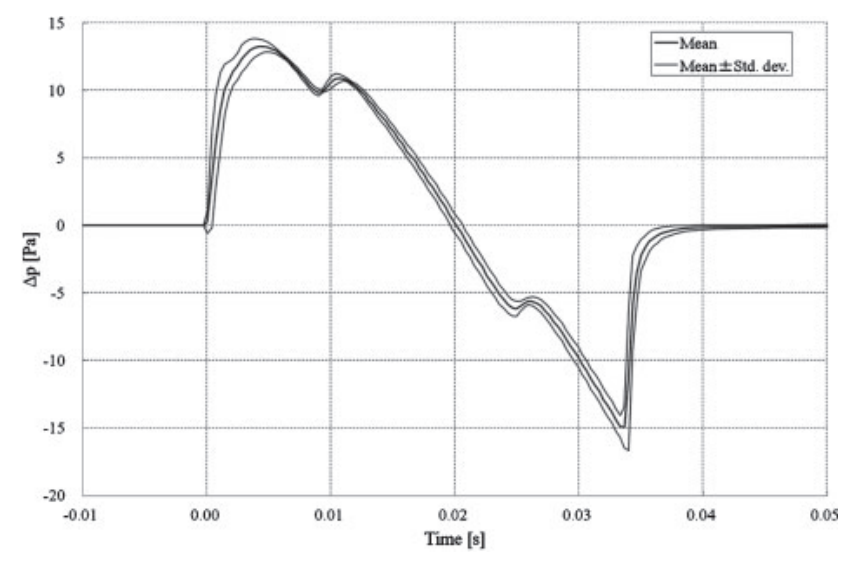

Fig. 9. Sonic boom signature under conditions of wind velocity uncertainty.

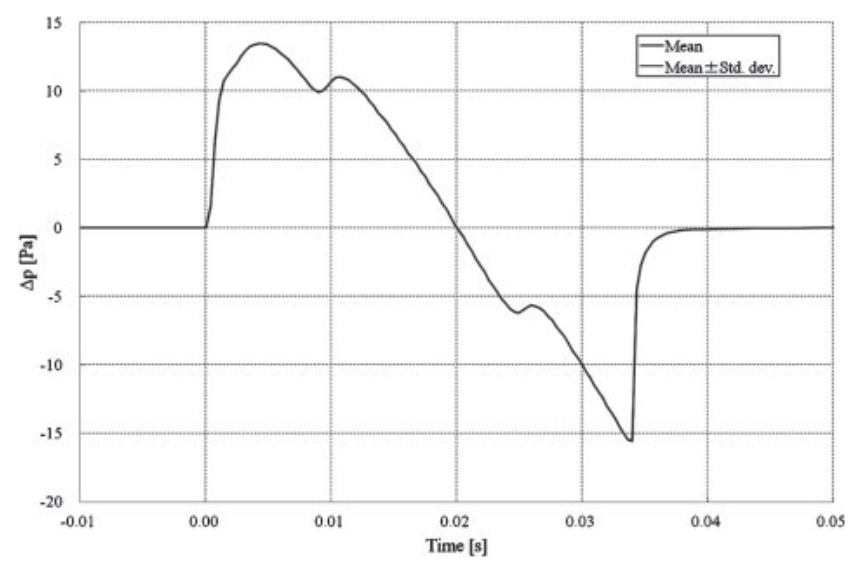

Fig. 9. Sonic boom signature under conditions of wind velocity uncertainty. 